\title{
Relationship Between Job Satisfaction and Turnover Intention
}

\author{
Aliya Alam (Corresponding author) \\ Karachi University Business School, University of Karachi, \\ KU Circular Road, University of Karachi, Karachi, Pakistan
}

Dr. Muhammad Asim

Karachi University Business School, University of Karachi

KU Circular Road, University of Karachi, Karachi, Pakistan

Received: Apr. 6, 2019 Accepted: Apr. 17, 2019 Online published: Apr. 18, 2019

doi:10.5296/ijhrs.v9i2.14618 URL: https://doi.org/10.5296/ijhrs.v9i2.14618

\begin{abstract}
This study examines the level of job satisfaction and turnover intention among nurses in Karachi. The objectives of this study is to examine the impact and relationship of satisfaction with organizational policies and strategies, satisfaction with supervision, compensation levels, task clarity, and career development on turnover intention. An instrument based on five facets of job satisfaction and turnover intention was developed based on literature reviews to find out the level of job satisfaction and turnover intention. For this purpose data were collected from 400 nurses working in different hospitals of Karachi. The findings shows that satisfaction with organizational policies and strategies, satisfaction with supervision, compensation levels, task clarity, and career development all have significant negative correlation with turnover intention and overall job satisfaction was found to have a significant negative association with turnover intention.
\end{abstract}

Keywords: job satisfaction, nurses, turnover intention, Karachi

\section{Introduction}

Workers are said to be the important part of the organization so satisfaction with the job is said to be the important factor that leads to the intention of leave. Turnover is affected by attitude of workers; it could have a positive or a negative impact both in the industry. When there is an increase in the intention to leave it results in creating a bad impact on the health care sector. If an employee leaves the company so that would be expensive and the new 
recruited person will need time to adjust or it will be costly. While in the health sector payments of salary are the key factors that lead towards the satisfaction with job. It gives internally satisfaction to the person moreover it can be increased by awarding promotion incentives and task according to the demand of worker. Several studies have been conducted on turn over intention of nurses and finding the reason that lead to the intention to leave. The culture of employee influenced worker satisfaction with job give them better opportunity for worker and better environment for the worker this factor may influence satisfaction with the job.

Nurses in medical staff are the most valued members of the medical institution who take care of the closest one for 24 hours in hospitals. Most of the nurses are in the consideration of the doctors. Mostly the nursing staff performs many duties in the medical institutions but still they are not paid according to their needs. Similar situation has been seen in the research conducted in Malaysia (Alam \& Muhammad, 2010) satisfaction with pay is said to be the basic goal of the worker to overcome the financial crisis, this results in effecting on the individual and as well as the organizational performance. If nurse's intention to leave the organization is high so it ends up creating a negative impact on the medical institution. In order to overcome this employee should be given better opportunity so that they can excel and make the organizational tasks achievable. Satisfaction with job is a major role for nurses. Intention to leave in any Medicare would be disaster for patients. In the field of research many researchers are determining to find the key factors of the intention to leave.

The shortage in nurses in the health industry always creates a bad impact, if it happens due to the intention to leave. To retain their employee or nurses it is the Human Resource management's responsibility to maintain their workers or nurses by giving them good pay roles. Focus on the factors those results in creating problems regarding satisfaction with job. To form a healthy environment culture give benefits to the workers and give small task rather than giving a huge responsibility. Give the tasks that are suitable and easily achievable for the worker and give chances to move forward in a company for growth. Regarding working condition many of cases have been reported that includes supervisor's attitude, working conditions, policies and the healthy environment. Every country has different working conditions so provide conditions that can be best fitted for the organization to overcome the turnover intention. So our focus of study as given below that would be the region of study.

Our focus of study is to find out the relation of satisfaction with the job along with the strategy, behavior of supervisor, compensation and task clarity that further leads to dissatisfaction with work resulting in turnover intention of the nurses associated with health sector.

\subsection{Statement of Problem}

(Sahadev \& Keyoor, 2008) Satisfaction with the job is said to be a multidimensional concept so it gets very important to see the aspects on which satisfaction with job affects employee's turnover intention in their current organization. According to many studies carried it is said that satisfaction with the job is the most important factor that predicts the turnover intention.

There have been many researches carried on satisfaction with job on sales persons that have 
followed an approach which defines and also measure satisfaction with the job. Many researchers have defined the satisfaction with job in seven types that are, supervision, fellow workers, job, pay, policy, advancement and promotion.

As observed by the results of different studies it is suggested that the relationships of colleagues and work environment have positive results on job satisfaction. If the organizations will provide a good working environment and assist in creating pleasant coworker relationships among workers it can enhance the job satisfaction successfully. Furthermore, the level of salary and job satisfaction does not affect the turnover intention directly but the level of salary and job satisfaction indirectly affects the turnover rate of employees. Additionally the greater the level of salary the greater the level of job satisfaction and the greater will be the organizational commitment and this greater level of organizational commitment will lead to lower intention to quit.

When an employee moves physically or quits the organization so it is termed as the intention to leave. According to (Carmeli \& Weisberg, 2006) this term turnover intention has 3 basic elements that are, thoughts to leave the job, searching another job and the intention to leave the organization. The intention to quit is based on the number of factors that include peers, management, union, compensation, experience but we only consider the compensation factor. Discussing the factors that affects employee turnover intention it was examined that the relationships of people working together; colleagues, level of salary, working environment, organizational commitment are significant factor that manipulate turnover intention of employee. As level of salary, job satisfaction indirectly affects the turnover rate of employees through organizational commitment; employees will start identifying the company's goals, business strategies and their jobs if the company's organizational commitment is well improved.

(Islam, Ahmed, \& Khan, 2013) States that in service sector (bank), employees' turnover intention reduces when they learn the culture of the organization and when they are supported by the senior members of the Organization. Further, this study states that employee's emotional attachment to the organization is very important to reduce their turnover intention. Therefore the relationship amongst intention to leave and commitment with organization is said to be negative.

According to the finding of (Halepota \& Shah, 2010) in research paper "An empirical investigation of organizational antecedents on employee job satisfaction in a developing country" the perception regarding organizational justice, level of team work and the on job trainings has positive impact on satisfaction with the job. It is also said that the job clarity perception isn't positive and significant to satisfaction of job of employee. The research states that organizational justice and team spirit highly affect employee satisfaction with job whereas the less job satisfaction was reported due to the lack in clarity of job in the country particularly in public sector health institutions of Pakistan.

From our base paper we have taken the relation between satisfaction with job and the intention to quit into our consideration. According to our topic, job satisfaction is taken as independent variable and turnover intention is taken as dependent variable. Our problem is 
dependent variable that is turnover intention. The solution in terms of job satisfaction that would help to reduce turnover intention are: satisfaction with policies and strategies, compensation, supervisor behavior, task clarity and with the career prospects in the organization.

In the light of many previous researches it is concluded that the satisfaction with the job is said to be an important factor of the intention to leave the organization. Hence, this research examines the impact of satisfaction with organizational policies and strategies, satisfaction with supervision, compensation levels, task clarity, and career development on intention to leave.

\subsection{Significance of Study}

This study will measure job satisfaction and its impact on turnover intention in the health sector which includes the nursing staff of different hospitals operating in Karachi. Many of these types of researches have been conducted in different countries around the world but in Pakistan very few researches are made on measuring satisfaction with job and its impact on intention to leave. This study helps the policy makers and managers of hospitals to determine the needs of nurses. Another important aspect of this study is that this study is conducted in a country where most of the people belong to lower income level. This study is also helpful for the managers of the hospitals to train new nursing staff. This research is based on five aspects of job satisfaction which include satisfaction with HR policies and strategies, with compensation, with supervisory behavior, with task clarity and with career development and their implication are that the managers should develop HR policies which are useful in retaining the nurses and which lessons the risk of nurses of leaving the organization. Affective compensation policies should be used which attract and retain the nursing staff. The leadership of hospital's supervisors is critical to inspire the nursing staff and helpful creating a better workplace environment. The nursing staff should be well guided to their regular responsibilities and finally there must be opportunities for the nursing staff towards future prospects of their career growth. These are the things which make the nursing staff satisfied and motivated and ultimately results in retaining in their current position.

\subsection{Research Objectives and Questions}

RO1: To examine the relationship among satisfaction with organizational policies and strategies, satisfaction with supervision, satisfaction with compensation levels, satisfaction with task clarity and career development and intention to leave.

RO2: To examine the impact of satisfaction with organizational policies and strategies, satisfaction with supervisor, satisfaction with compensation levels, satisfaction with task clarity and career development on intention to leave.

RQ1: Does satisfaction with organizational policies and strategies, satisfaction with supervisor, satisfaction with compensation levels, satisfaction with task clarity, satisfaction with the career development and turnover intention have any relationship?

RQ2: Does satisfaction with organizational policies and strategies, satisfaction with 
supervisor, satisfaction with compensation levels, satisfaction with task clarity, and satisfaction with the career development have impact upon turnover intention?

\subsection{Definition of Terms}

\subsubsection{Job Satisfaction}

It is the feeling of pleasure and achievement which comes from policies of human resource, compensation, supervision, task clarity and career growth that employees experience in doing a job when they realize that their work is worth doing. (Purani \& Sahadev, 2008)

\subsubsection{Turnover Intention}

Turnover intention is the rate at which workers joins and leaves the organization. In other words, it means how long employees tend to stay in the organization.

According to our topic, job satisfaction is taken as independent variable and turnover intention is taken as dependent variable. Our problem is dependent variable that is turnover intention.

\section{Literature Review}

This chapter discusses the material which is mainly related to "job satisfaction" and "turnover intention" of employees working in different areas and field. This literature review contains the researches in which some other variables are also studied alongside job satisfaction and turnover intention which include organizational commitment and industrial relations which are used as a moderating variable between job satisfaction and turnover intentions of employees. This literature was very helpful in the development of theoretical framework for the study. Although job satisfaction and turnover intention is measured in variety of organizations and industries but this literature contains the researches which is mostly related to examining the job satisfaction and turnover intention in health care sectors employees which are nurses. The presentations of the literature review are as follows.

According to (Ali \& Baloch, 2008) there are some factors that contribute on the intention to leave of private sector school teachers of Charsadda district. These consists 10 facets of work satisfaction in which there is satisfaction with principal, with pay, colleagues, the working condition, recognition, promotion, students and also social status and how these all impact on their intention to leave. To collect the data for this study a schedule was used that had questions about satisfaction with security, pay, nature of work, supervision and all other factors that affected the turnover rate. To measure satisfaction with the working condition, security, promotion and integration Minnesota Questionnaire was used. To measure status, nature of the work, pay, students and principal a questionnaire was used by Wong ting-Hong and for intention to leave Michigan Organizational Assessment's questionnaire was used. To test the hypothesis Pearson correlation and zero order correlation was used. The turnover intention is dependent on 10 job facets. Research findings show that 3 out of 10 job facets contribute to turnover intentions. The 3 facets pay, security and promotion are highly negatively related to turnover intention. 
Likely, according to (Aydogdu \& Asikgil, 2011) the factors that contribute to job satisfaction are: pay, work itself, supervision, promotion possibilities, peer and working conditions. The main reason behind this study is to look behind reasons in the relationship of organizational commitment, satisfaction with the job and the intention to leave from organization is said as intention to leave. The independent variables are "organizational commitment" and "satisfaction with job" while "intention to leave" is said to be the dependent variable. Two organizations in Istanbul were taken as a sample for this study. One organization is mainly in the service provider whereas the other in production area. These both organizations are of private sectors. Data gathering was done through questionnaire which consists of 4 sections in first section of questionnaire there are demographic variable. Job satisfaction questionnaire was used to see the satisfaction level. (Meyer \& Allen, 1991) designed an eighteen item scale to measure organizational commitment. The three subscales were normative, affective and continuance commitment. These all subscales were measured from strongly agree to strongly disagree and correlation was applied on the findings of the data. The research findings are that commitment with organization and satisfaction level of job is in a positive relationship. And these two variables have a negative impact on the intention to leave.

On the contrary, according to the authors (Joo \& Park, 2010) in research paper they have studied the various variables that lead to intention to leave of an employee. When it comes to the field of Human resource and organizational development the satisfaction with career, intention to quit and the commitment to organization are considered very important. Conducted research helps us to find about the impact of personal characteristics on an employee's organizational commitment, satisfaction with career and intention to leave. From Korea 500 companies participated in this study, which were from diverse set of industries such as finance, trading and manufacturing. From each company the participants who received their email for participation were selected by the HR manager. To obtain the individual perception they held online survey that was self-administered. Out of the employees that counted to 500, 241 responses were collected. Correlation, hierarchical multiple regression analysis, reliabilities and descriptive statistics was analyzed by using SPSS. The things that came out as an antecedent for the intention to leave were organizational commitment, career satisfaction and learning culture of the organization. In this paper contextual and personal factors have been studied that contributes to organizational commitment and career satisfaction. These factors had an impact on intention to leave. Further this study suggested that future researches should conduct research on the basis of diverse demographic cohorts. Moreover, research should be conducted on different educational backgrounds.

Similarly, other authors studied about some of the alternatives and rewards by which we can predict the turnover intention. Just like, (Lance, 1988) in research paper "Job performance as a moderator of the satisfaction-turnover intention relation: An empirical contrast of two perspectives", put the United States telecommunications firms (previous competing predictions) to test field employees. They made questionnaire and the surveys were taken place in grouped sessions. The field employees were taken as the participants of research who were from the telecommunication firm which had its headquarter situated in United States. 


\section{Mll Macrothink}

International Journal of Human Resource Studies

ISSN 2162-3058

2019, Vol. 9, No. 2

Total sample of employees was 2750 and it they were categorized according to their job types. The result indicates that the turnover intention of the employees who performed higher was less as compare to those who performed less or average their turnover intention was higher than the rest. The results that were found were mostly mixed but they were in support of the hypothesis drawn. Statistical correlation between intention to leave and performance were negative.

Another study, which was carried by (Gamage \& Buddhika, 2013) is to identify the correspondence that is in between turnover intention and job satisfaction of IT professionals in Sri Lanka. The major problem that is faced by IT companies of Sri Lanka is Turnover Intention of employees, This research study highlight some important factors and reasons that cause high employee turnover and then intend to provide a strategic roadmap which would enable reduce the number of employees leaving IT companies in future. In this paper satisfaction with job has six facets that are satisfaction with variety, supervisor, compensation, closure, HR policies and Satisfaction with co-workers. The conceptual framework is that the six job satisfactions facets are said to be independent variables and turnover intention from the organization is the dependent variable. The population and sample determination was based on the survey done by Sri Lanka Information and Communication Technology Association (SLICTA). The sample size is of 300 IT professionals. Convenient sampling technique is used as oppose to the simple random sampling technique because it is not possible to access to the total population. Data was collected by questionnaire. The questionnaires would mainly be through internet based online questionnaire. To spot out the relationship present between the variables correlation analysis has been used. The finding of this research showed a notable negative relationship between the intention to leave and the satisfaction with the job amongst IT professionals.

According to a research carried in one of the supermarket chain in Malaysia by (Salleh, Nair, \& Harun, 2012). This research paper tends to find out the level of organizational commitment, satisfaction with job and intention to leave among the employees working at a retail company of Malaysia. The findings from the studies of retail sector have also (Arndt, Arnold, \& Landry, 2006). In various studies there is seen a strong relation between intention to leave and organizational commitment. On the basis of these relations in between organizational commitment, satisfaction with work and intention to leave the research framework had been developed. Research framework for this study is that the independent variables are organizational commitment and job satisfaction whereas intention to leave is the dependent variable. A questionnaire was developed which had questions about the respondent's satisfaction, demographic information, commitment with the organization and the intention to leave. Job descriptive index was used to measure the job satisfaction. The JDI measured satisfaction in 5 aspects which were promotion, salary, work, coworkers and supervision. To seek the organizational commitment of the employees a questionnaire was developed. Company's Human Resource Department fully coordinated for this study. For this research the questionnaires were distributed among hundred 100 employees (Executive and Non-executive) the result gave empirical findings that all the factors had an effect in the intention to leave. 


\section{Mll Macrothink}

International Journal of Human Resource Studies

ISSN 2162-3058

2019, Vol. 9, No. 2

This study used to carry out how the leadership affect turnover rate. This research gives the idea how leadership can help the managers to supervise their employees. Taking, supervision factor into account the authors (Chen, Friedman, \& Simons, 2014) stated in "The gendered trickle-down effect: how mid-level manager's satisfaction with senior managers' supervision affects line employee's turnover intentions", that knowing about trickle-down effect is important since the ultimate driver of bad supervisor-employee relations may be bad senior-management supervisor relations. To conduct this study, sample of 1,527 full-time employees in 267 different departments at 94 hotels in the USA and Canada was taken. Departments with one identifiable manager were included. The reason for this was that the author was interested in the effects of the manager's gender and his or her own satisfaction with supervision on employee work attitudes. The participation in the research was totally voluntary. To measure all the attitudinal constructs they used a Likert-scale. Hierarchical linear modeling is used to examine the data that was collected. Results show that middle manager's satisfaction with senior managers was related positively to line employee's satisfaction with middle managers, which in turn, was correlated positively with line employee's intentions to remain. Further, it was found that middle manager's gender moderated the relationship between middle manager's satisfaction with supervision and line employee's satisfaction with supervision, the relationship was stronger when the middle manager was female. Moreover, this study suggested that future research needs to identify which levels of manager satisfaction are too distant to have an effect on line employee's intention to stay.

According to the finding of (Yuan, Yu, Li, \& Ning, 2014) in research paper "Occupational commitment, industrial relations and turnover intention", occupational commitment is beneficial for industrial relations, while this relationship is conditioned on employees' turnover intention. In this research the direct effect occupational commitments types have been empirically studied that is normative, affective, occupational commitment and cumulative costs \&limited choices, on industrial relations in the context of Chinese firms. To conduct this study, 50 masters of business administration students and $10 \mathrm{PhD}$ students completed the pilot questionnaire to improve the clarity of the language and presentation of all items of the questionnaire. The formal survey was administered in firms located in Beijing, Shanghai, Hunan and Guangdong. A total of 600 copies of questionnaires were sent out by post or email to firms and 429 valid responses were finally obtained, yielding a response rate of approximately $71.5 \%$. Results show that except for limited choices, the other three types of occupational commitment are positively related to industrial relations. This result reveals employees that are emotionally strong with their workplace and their occupation are more focused at performing their current work and more easily realize their organizational identity. The direct and moderating effects of employees' turnover intention are another two key points in the present study. The empirical estimations suggest this that the intention to leave is negatively related to the industrial relations. This negative effect is consistent in all econometric models, which implies that those working employees who have a higher level of turnover intention, leave their current job are less likely to care about their relationship with their current workplace. It is found that turnover intention negatively moderates the relationships between employees' occupational commitment and industrial relations. For 
further research work, the authors of this study recommended to check the results of the present research in other contexts.

Likewise in previous study here also relationship between the variables is identified (Cole \& Bruch, 2006) clarifies the differences in functions between the organizational commitment, identity strength and identification. To conduct the research data was obtained from large steel manufacturer $n=10948$. Firstly to determine the discriminate validity confirmatory factor analysis was used. It suggests the differences on the basis of hierarchy so all the authors decided to examine all the levels that were officers, middle management and workers. Than to finally estimate the correlation that was in between organizational identification, turnover intention, commitment with organization and organization identity strength multi group structural equation was applied. This study concluded that all of these variables tend to the employees intention to leave. In other words, it can be said that Organizational identity had a negative correlation with the turnover intention in the hierarchical groups. There existed a negative correlation between commitment and turnover in 2 groups. In the group of workers there also was a negative correlation of identification with intention to leave. The findings have suggested that the perceptions of strong organizational commitment, identification and identity might have an impact on intention to leave in numerous ways.

(Alam \& Muhammad, 2010) The area of research for this study is different as compare to previous this research take account of the health workers satisfaction level. The main objective behind this study carried was to find out the level of turnover intention and satisfaction with job of nurses from Malaysia. For this study the sample consisted of 153 nurses from one of Perlis's public sector hospital. The nurses also went under a cross sectional survey in the hospital. Only those nurses who were registered and who had license to serve in public hospitals were considered as the population of the research. Total 200 questionnaires had been distributed out of which 173 came back in return. In the questionnaire the applicants were required to fill in their some personal characteristics too like age, income, gender education etc. after this a categorical scale was used to measure these things. The results showed that there are some of the factors because of which the employees get less satisfied and tend to leave the organization they are working with. The factors are HR Management Policies. If the HRM practices in order to the health staff and the nursing sector in the hospital are improved so the chances can be minimum for intention to leave. It is also been studied that if it is ensured that outcomes of these policies will motivate and satisfy them than there will be a decrease in the turnover intention in the nursing workforce and the staff would work more selflessly.

(Murrar \& Hamad, 2013) This research is somewhat like previously discussed research in which job satisfaction is measure in IT firms of Sri Lanka. As the job satisfaction relationship with turnover intention term is measured by various author in different countries IT firms but this research has not be done in developing countries. This research intends to examine what was the relationship between intention to leave and job satisfaction amongst employees. In this paper the job security is taken as additional independent variable as compare to the previous research. To collect the data on online questionnaire was developed. Five IT companies were used to gather data. The technique that was used is random sampling. 
Correlation analysis and data descriptive statistics is used for analyzing the data collected. The overall findings showed that the work conditions and pay benefits, nature with work career advancement, supervision and management were all significantly correlated. This study also discusses the implications of the research. The data that was collected from the respondents was analyzed and tested using SPSS. Descriptive and inferential analyses both were carried out on the findings.

Again here is the example of health worker job satisfaction research. (Loncar, 2010) Investigates the relationship amongst job satisfaction, turnover intention and pay satisfaction and how it affects the employees. For this purpose data from 200 registered nurses of a hospital were analyzed. After the regression tool was applied it was observed that the nurses who were satisfied with their pays were happy with their jobs and had no intention to quit their jobs whereas those nurses who had low pays were unsatisfied to an extinct and lead to turnover intention. This research paper also gave some of the recommendations that can reduce turnover among nurses. For this study a questionnaire was made and distributed amongst 455 full time and 128 part time working nurses. The method that was chosen that was random sampling. They mailed the questionnaires and asked them to give in their voluntary input in-return 202 nurses gave their answers out of which 200 were considered. In order to analyze the data, descriptive statistics and reliability analysis were used. Further, standard deviation and correlation were also applied on the findings. After applying the concepts the result that derives from this study is that turnover intention is caused by insufficient pay roles of nurses in health sector. This leads them to leave the organization that is termed as turnover.

(Park \& Kim, 2009) This is also a research for measuring nurses' satisfaction level. This research measures whether the culture in organization affect satisfaction level of nurses. The main reason and purpose to have this study was to examine various cultures of organizations that have been linked with satisfaction of job and intention to leave among nurses of Korean hospitals where normally the culture of work is considered different as compare to western countries. For this study 527 nurses are taken as sample size from two public hospitals of Korea. For the purpose of assessing the culture of organizations, previously validated 20-item instrument was used. In order to measure satisfaction with job and intention to leave self-report questionnaire were used. Results of the study show that all organizational cultures were not equal, they varies. Among all, the most useful culture of organization is "consensual culture" which showed a strong and powerful link with higher satisfaction with job and lower turnover intention. According to one of the main finding of this study, the effect of mediator that is satisfaction with job was significant statistically on turnover intention. This finding proves that in order to make organizational loyalty and retention rate better, nurses should get warm brace from the peers and manager of department.

As compare to nurses this paper studied the satisfaction level of $R \& D$ personnel. The main objective of (Chen, Chang, \& Yeh, 2004) research paper was to identify the needs of career and career development to see its effects on variables that are satisfaction with job and intention to leave. This paper also includes the empirical testing of the space between programs of development for career and career needs and the examination of the gap 
influencing the satisfaction of job and the intention of leave. The study was carried out in "Hsinchu Science-based Industrial Park" situated in the north side of Taiwan. To conduct this research, the method used to collect data was questionnaire. These questionnaires were filed by 367 personnel of R\&D. Further, regression analysis and five point "Likert-type response scale" was used. It was exposed from the result of this study that depending on the stages of their career, the need for career development gets diverse.

Moreover, the result shows that due to more gaps between programs of development for career and career needs the level of intention to leave and job dissatisfaction increases. Therefore, managers who fail to provide and satisfy the career needs of $R \& D$ personnel will face greater dissatisfaction due to which their work will also be affected in negative way.

Similarly this research is related to health workers satisfaction. (Blaauw, et al., 2013) The main objective behind the study to carried out what is the relationship of satisfaction with job on turnover intention in South Africa, Tazania and Malawia health workers. In this research cluster sampling was used. The total sample consisted of 2220 workers. The participants were given a self-administered questionnaire. The variables were studied by applying the multiple regressions on them. After applying this tool there were seen some differences amongst these 3 countries in terms of these variables. By this paper it was also confirmed that the turnover intention is related to the satisfaction with the job. Additional analysis is going to be needed to properly justify a number of the patterns that the man of science have discovered and investigate their significance for health service delivery.

(Martin \& Roodt) Here the new concept of studying job satisfaction is utilized. This study is all about a company that experiences a merger. This study investigates the perception of a tertiary organization about a post-merger. For the employees of tertiary institution of South Africa a model was made that can predict the level of intention to leave. To incorporate different methods for linear regression they built a systematic model-building. In this research paper the variable that has been mostly studied is the satisfaction with job. The intention to leave is said as a process that has 3 different stages that are decisional, attitudinal and behavioral. 367 employees of this organization were taken as the ample for this study. The response rate turned out to be 16 percent. The administrative and research personnel were the population. The tools that were used to measure the data were turnover intention, Organizational commitment and Minnesota Satisfaction questionnaire. In between both the intention to leave and satisfaction with job there was strong correlation. This study predicted $47 \%$ variance in the intention of leave.

This study is carried out to understand how the turnover influences by commitment and satisfaction in organization. (Tnay \& Slong, 2013) The main focus of this research was to seek what are the effects of commitment with organization and satisfaction with job on the intention to leave of employees working in a production industry. In this study, job satisfaction (Satisfaction with Pay and Supervisory Support) and organizational commitment are taken as independent variables while employee's turnover intention is taken as dependent variable. To conduct this study a 100 questionnaire were distributed in the organization out of that in return 85 came back. To test the data the statistical tools that were used were 
inferential and descriptive statistic. To measure the relationship between the dependent and the independent variables Pearson Correlation Coefficient were taken. The result of this study implied that the independent variables were in a negative relationship with the intention to leave of employees. Whereas as the commitment with organization did not had any impact on the intention to leave of the working employees in the organization. The author recommends that future research should study on similar research framework at different population group such as the banking, telecommunication, hospitality or even the manufacturing industry.

(Biswas, 2010) This research paper studied about the two variables, satisfaction with job and involvement with job as a mediator among the turnover intention of employees and the psychological climate \& further expands the study to its impact on organizational effectiveness. For this study the data was collected. The sample consisted of 357 managers from different organizations were selected on random. Of the 357 participants, 180 were from manufacturing companies which makes $50.42 \%$ while 177 participants were from service sector which makes $49.58 \%$. To determine job satisfaction, an 11 item instrument was used. The instrument enclosed extrinsic, intrinsic and social satisfactions which are the three extent of satisfaction. Affective attachments of individuals scale were measured with their job. Four items measured turnover intention (O'Reilly, Chatman, \& Caldwell, 1991). For the purpose of analyzing the data multivariate data was used. According to the results of instruments used in this study, "psychological climate is a statistically major analyst of organizational effectiveness and the two variables job satisfaction and job involvement are significant intermediaries in broadcasting the influence of the analyst variables to the criterion variables."

(Ozbag \& Ceyhun, 2014) This research add new dimension of work-family conflict. This study investigated the reconciling effects of satisfaction with job on the relation between work-family conflict and intention to leave. In order to carry out this study, a sample of 100 Turkish Marine Pilots were taken. To analyze the data SPSS statistical packet program was used. In order to measure the significance of conciliation effect of job satisfaction the Sobel test was used. To inspect mutual effects of personal characteristics, work characteristics, WFC (work family conflict) and satisfaction with job on turnover intentions, author conducted a series of hierarchical regression analyses. First two steps inspected the effects of personal characteristics, work characteristics and WFC (work family conflict) on turnover intentions. The conclusion exposed that shifting system and WFC have a positive outcome on turnover intentions whereas numbers of exercise and job satisfaction have a negative outcome on turnover intentions. Unlike previous studies, the finding also pointed out that there is no considerable conciliation effect in relationship between the respondents' WFC and turnover. It overall concludes, higher level of satisfaction with job is linked with lower level of turnover intentions May be because employees who are satisfied are more effective in handling WFC. However, the finding indicates that the effect of satisfaction of job on the turnover in relationship with WFC (work family conflict) was not significant.

This research again concentrated on purely aspects of job satisfaction. (Carraher, 2011) studied the turnover of workers and businessman on their attitudes towards benefits, satisfaction with pay, age and gender from countries like Estonia, Latvia and Lithuania across 
a time frame of four year. A survey was conducted on attitudes towards satisfaction with pay and benefits. The data was collected from 153 employees and 103 businessman of Estonia, 157 employees and 243 businessman of Latvia, and 146 employees and 109 businessman of Lithuania. In order to conduct this research regression equation method was used and actual salary or pay data was obtained from organization's internal record. From results of the study, it was exposed that major predictors of intention to leave for workers and businessman were attitude towards benefits while pay satisfaction was significant only for employees. Further it was also observed that "equity and expectancy considerations" were helpful to explain differences in rates of turnover intention while only "expectancy theory consideration" was helpful for business owners. It was concluded that in order to retain and attract employees, benefits and pay are very important.

(Lotfi \& Pour, 2013) Apart from job satisfaction this study contains a different variable which is justice in organization. This study was conducted to investigate the relation among organizational justice and job satisfaction of Tehran Payame Noor University employees. Organizational justice in the place of work means that employees are vital for the organization. Apparently it was observed that injustice had some unfavorable impact on the strength of collective work, because it highlights staffs motivation and the dedication by human resource. Statistical Society of this study includes all personnel of the organization (800 people) in 2012 and the sample size includes 260 people that were selected randomly. This study was of descriptive-analytic type and for data collection, organizational justice (Niehoff \& Moorman, 1993) and job satisfaction (Spector, 1997) questionnaires were used. For analyzing the data, statistical methods like Multiple Regression and Pearson Correlation Coefficient were utilized. Results of this study showed significant relation between organizational justice and job satisfaction. It is observed from this study that only procedural justice is able to predict job satisfaction. Apparently, the ones who feel satisfied about the organization's policies towards equity will have more job satisfaction.

(Monis \& Sreedhara, 2011) In this study two firms are selected for the measurement of satisfaction level of employee also with career development. This is an empirical research and it was conducted on 10 firms' operating in India out of which 5 are Indian and 5 are foreign MNC BPO firms. These firms are ranked amongst the top 100 for year 2009. In this paper perception employees of foreign and Indian firms in context to career development practices were analyzed and evaluated. Further, the factors that influence the employee satisfaction towards career development practices were compared and analyzed. For this purpose, the data was collected through both qualitative and quantitative method. The sample consists of 243 employees and 163 employees of Indian MNCs and foreign MNCs respectively. In order to conduct this study, secondary and primary data were used. Primary data was collected by questionnaire from 10 MNC BPO companies, 5 from India and 5 from foreign which were chosen on the basis of ranking five point scales. Through the result of Likert scale, it was found that the satisfaction level towards the career development is 69.71 percent and 69.82 percent among the participants of foreign and Indian firms operating in India. Further, the results of regression analysis shows significant positive relationship of variables affiliated with the respondent's satisfaction of Indian and foreign MNC BPO firms 
towards the career development practices.

This research targeted the banking sector area. (Rahman \& Iqbal, 2013) researched about the significant factor which identifies the level of satisfaction of job of commercial banks employees operating in Bangladesh. To conduct this study, 48 employees were taken that were chosen from 8 banks of Bangladesh. To gather the data from the sample a structured questionnaire was taken. They used both primary and secondary data in order to perform this study. According to this research work, turnover intention was seen as one's behavioral intention to quit job. By applying the statistical tools the conclusion that came are some of the factors that influence satisfaction with job and intention to leave. These factors are, "job security, location of bank, employee's autonomy, basic salary \& fringe benefits, career advancement opportunity, performance appraisal process \& evaluation, goodwill of the bank, working environment, working schedule, peers relation among the employees etc." As a result, this research work shows a strong relation found in between turnover intention and job satisfaction in the Bangladesh private commercial banks.

(Issa, Ahmad, \& Gelaidan, 2013) This research is from the point of view of sales person satisfaction in job. This research was conducted in pharmaceutical stores in Amman to find out the relation of intention to quit and satisfaction of job of the sales representatives. For this study 200 respondents among the sales person were randomly chosen from the sales field. The statistical tool that was used was multiple regression correlation and descriptive analysis. The result of the study highlighted that pay satisfaction was the leading dimension of job satisfaction when it comes to turnover intention. Therefore, having high satisfaction will smoothly reduce the turnover intention among the employees. In the research paper the intention to leave has been measured by 4 items. The job satisfaction was measured through Questionnaire (MSQ) it was measured by 19 items adapted from JDI and MSQ. The data analyzed that satisfaction with job and intention to quit had a negative relation with each other furthermore it was realized that satisfaction with pay was the leading dimension.

(Mbah \& Ikemefuna, 2012) This research include only three facets of job satisfaction is taken. This study was carried out on satisfaction of job and employees intention to leave in Lagos State in Total Nigeria. It was observed that three causes that lead to employee turnover intention are satisfaction with pay, nature of work and supervision. For this study questionnaire, interviews and reviewing relevant journals in this field of study were used. In order to conduct this study the company was surveyed and 300 employees of company were selected. The data collected was primary data. Interview was conducted in the presence of 3 Human Resource Executives in which the detailed discussion was held on the questions that were included in questionnaires. According to the findings of this research it is concluded that higher the job satisfaction, less will be the turnover intention. In other words the employees who are satisfied with their jobs will not quit it which will eventually increase job satisfaction. Hence, it was found that Total Nigeria PLC follows standard pay structure, conductive nature of work and supervision in order to reduce employee's turnover and for the purpose of retention strategy.

(Yucel, 2012) This study was done to analyze the relationship among commitment with 
organization, satisfaction with job and intention to quit of employee. For this purpose they developed a model and tested on field. The test was conducted by taking 250 respondents which are employees in manufacturing company of Turkey. Intention to leave, satisfaction of job and commitment are well known research topic in this study the relationship among these variable are try to depicted through conceptual framework model in which first part is related with satisfaction in job which effects commitment to the organization, and then this effect on organizational commitment made impact on turnover intentions. To gather the data the method of personal interview is used because questionnaire originally in English language, so the bilingual speaker that hire for the purpose of translating the questionnaire need to translate the questionnaire, then it use for the data collection. To conduct the survey, a pair of two scholars of management was invited for reviewing study in order to give the detailed feedback. As they described, the effort for the modification of questionnaire was made and for the confirmation of reliability measures it was pretested on MBA class. Out of 250 employees 188 responded during regular working hours. The likert-scale which is widely used in the measurement of variables such as intention to leave, organizational commitment and satisfaction with job is used here. To test research hypothesis structural equation modeling, correlation and t-test was used through which demographic aspects of the respondents and consistency in data analysis scales was put to draw conclusions. From the study it is recognized that there has been significant relationships amongst the variables. The outcomes indicate that greater the level in satisfaction of job would result greater organizational commitment which eventually leads to lesser intentions of turnover. So the conclusion is that satisfaction in job has positive relation with commitment to the organization and negative relation with turnover intention.

In the above paragraph relation among three variable "commitment with organization, satisfaction with job and intention to leave" is discussed. The authors (Yin-Fah, Foon, Leong, \& Osman, 2010) also conducted the similar kind of research in which these three variables taken with another variable job stress. This study was conducted among the employees of private sectors in Petailing District, Selangor Darul Ehsan Malaysia. The main reason for conducting study over there was because of high turnover rate which was reported on March, 2008. The sample contains the 120 personnel responses that have diverse working background. The Collection of data was comprised of secondary and primary data source. To measure the organizational commitment the Organizational Commitment Questionnaire was used with 7 point likert-scale, to measure the Stress on job a 14 item scale with an ordinal arrangement of responses from very often to never, known as Perceived Stress Scale is taken, to ascertain satisfaction on job very famous questionnaire of university of Minnesota (MSQ) is taken and the last turnover intention of employee is measured by three-item measure. Then Pearson correlation method was implemented to examine the association among predictor variables which are job satisfaction, job stress, organizational commitment, and single response variable which is intention to leave. The result revealed that organizational commitments and job satisfaction have negative relation with intention to leave and the stress on job has positive relation with intention to leave. Furthermore concluded is that socio-demographic aspect of the respondents mediates the behavior of the variables commitment to organization, satisfaction with job, stress on job and intention to leave. 
(Mahdi, Zin, Nor, Sakat, \& Naim, 2012) This research has a different way of examine the most studied variable which is satisfaction on job with turnover intention. The satisfaction on job is divided into two categories intrinsic and extrinsic satisfaction with job these two taken as independent variable and used to see the impact on dependent variable which is intention to quit. The study was conducted among Malaysian printing company employees. Data were collected in control setting through the structured questionnaire. The distribution quantity is 36 out of which 32 returned back completely. The random sampling technique has been used in order to distribute the questionnaire. The questionnaire was divided into four categories. The first and second categories consist of co-workers, working condition, supervision and value of the work respectively. The likert-scale which is widely used in the measurement of job satisfaction was taken to specify respondents' replies. Third last category was used as a sign of measuring indication with multiple answers choice available to the respondents regarding their intention for leaving the organization and the fourth category based on responded personal which include also position whether executive or non-executive. For analyzing the data SPSS for windows is used. In addition to that correlation analyses were used to signify the relationship among three variables. In this research it is found that turnover intention has significant negative relation to intrinsic satisfaction in job compare to extrinsic satisfaction in job.

In previous research there is discussion about intrinsic job satisfaction (Galletta, Portoghese, $\&$ Battistelli, 2011) but here we talked about the factors job autonomy, intrinsic motivation, and commitment with affection which moderates their effect on intention to leave. For this purpose a cross-sectional design is prepared. The research included 525 registered nurses from a single hospital in the Italian Public Healthcare. Out of 525 nurses the responses of 442 are useful. Data were collected through a questionnaire paper. The distribution of questionnaire was done through a supervisor nurse of each unit. The questionnaire consists of two parts first consists of personal data and second part consists of the measure of variables taken in this research. Again affective commitment is measure through organizational commitment questionnaire, for the job autonomy Work Design Questionnaire (WDQ) is used. Intention to quit was measured in two item things. Regarding the data analyses many techniques are used in this research. This study was driven by job characteristics model and self-determination theory which delivers fresh understandings into the field of nursing, into the association among the variable associated with intention to leave. The outcome from this study delivers that intrinsic motivation and affective commitment both positively related to job autonomy. This study also showed the affective commitment mediation effect upon the relationship between intention to leave and job autonomy. The organizations should foster their commitment with affection related to organization since intention to leave is negatively related with it.

(Wang \& Yi, 2011) The above study is driven by JCM and SDT. Now this research is considered as improved way for understanding the inconsistency of findings on how leader member exchange theory points to turnover intention in Chinese companies. In this research satisfaction with job and job stress used to show a mediation path between LMX and intention to leave. In order to mediate the variables the first condition is that in the absence of 
mediator, predictor variable(s) must be allied with response variable(s). For the mediation process the second condition is that predictor variable(s) must be interrelated significantly with mediator. Therefore LMX should satisfy the both condition. In this study four manufacturing firms of China are participated. All of these four firms are owned by Chinese enterprise. For completing the survey the sample of 568 employees from all four organizations is taken. These organizations are consisted of manufacturing heavy and light industries. Most of the participants from these organizations were lower level worker, although there were supervisors and middle level manager. To measure the LMX a model proposed by (Liden \& Maslyn, 1998) is taken which consist of 12-item multidimensional scale. To measure the stress a scale composed of nine items is used in which simply list of stress related item is placed. Job descriptive Index model is taken for the measurement of 3 aspects of satisfaction with job that include satisfaction with supervisors, with co-workers, and with work in general. For measuring turnover intention the scale developed by (Hanisch $\&$ Hulin, 1990) is used. The likert-scale of five points is taken for all measures except job stress. The result established the relation that satisfaction with job is behaved as a mediating link between intention to leave and LMX whereas job stress fails to intermediary response between intention to leave and LMX.

(Bonenberger, Aikins, Akweongo, \& Wyss, 2014) This study purpose is how to improve motivation through motivating factors which creates satisfaction on job. This research study discovered the impression of motivation and satisfaction of job on the intention to leave. Satisfaction of job is frequently research in previous study while the motivation is not as frequently. These two variable job satisfaction and work motivation have been recognized as main cause of workers, which are related to health organization, for their intention to leave and retention in the middle as well as low income countries. The region or area for conducting this study is the Eastern part of Ghana which includes the following parts of districts namely north part of Akwapim, Manya Krobo upper part and west part of Kwahu. The tool for collecting data was in a form of well-organized questionnaire which gather statistical data on intention to leave, satisfaction with job and motivation. For the measurement of intention to quit the health worker were asked what their intention was for this purpose only dichotomous responses yes/no were used. The actual data collection was done by lead author and his two assistant between the months of September and November 2012. District Health Management Teams conducted the sampling which was based on staff inventory. The sampling hadn't comprised of executive and workforce support. Here the necessary sample size required, which was constructed with formula of Cochran's size of sample is nearer to 300. The study revealed that there is significant impact of satisfaction with job and motivation on intention to leave. Further that the greater heights of those two (motivation and satisfaction with job) minimized risk of workers' turnover intentions. These findings specify that with the use of effective HRM practices there is a way to inspire satisfaction of job and motivation that is the way to maintain the workers related to health at existing place.

In paper of (Alniacik, Alniacik, Erat, \& Akcin, 2013) "the moderating effect of person-organization fits on the relationships between satisfaction with job, affective 
organizational commitment and intention to leave." Person-organization (P-O) fit has been defined in various ways as value similarity, goal similarity, and the go with between employees' needs and reinforces available in the work environment, and the go with between the personality of the individual and the characteristics of the organization (Chatman, 1991) and (McCulloch \& Turban, 2007). Affective organizational commitment, satisfaction with job and intention to quit is common in many of the researches done. Empirical evidence in the current study has already showed that job satisfaction of employee and his commitment to the organization have negative relationship with turnover intention. The research model proposed for this study showed that the independent variable are satisfaction with job and affective commitment and satisfaction with job while moderating variable is person organization fit is moderating variable and turnover intention is dependent variable. The research model shows that PO- fit moderates the effect of satisfaction with job and affective commitment on the intention to leave. The data was collected for a field research from a representative sample of academic and administrative staff who worked at higher education institutions in Turkey. The mode of collecting data is online questionnaire. Out of 1247 academic and administrative staffs working at 32 state universities 212 valid responses are considered. For the analyses of data questionnaire are converted into code and entered into the SPSS spreadsheet for the purpose of data analyses. In order to realize the independent relation of each variable correlation among the variable is used. The study find out that job satisfaction was observed a positive ion and affective commitment both are considerably in a negative relation with intention to leave. But there was noted a positive relation between satisfaction with job, affective commitment with person organization fit.

"Career motivation is clear in terms of its three main components which are said to be as: career identity, career insight and career resilience" (Alniacik, Alniacik, Erat, \& Akcin, 2012). The objective of this paper is to study what relation does affective commitment, career motivation have on satisfaction with job. For the purpose of testing the hypothesis a field research was designed with help of survey methodology. The tool using for the collection of data was a questionnaire. The questionnaire also included demographic questions and the integrated career motivation scale which was developed by (Grzeda \& Prince, 1997). The sampling technique used is convenient sampling with a size of 250 employees which were working in various industries which embrace banking, education, automotive; finance and higher education. Questionnaires were dispatched through emails. The questionnaires were uploaded in SPSS spreadsheet to perform the analyses. Principal component analyzed "the factor structure of the career motivation scale." Correlation technique is used to know variables and their relationships on each other. It have been concluded that there was a significant positive relationship of career motivation with satisfaction with job and affective commitment.

(Dardar, Jusoh, \& Rasli, 2012) Turnover intention has been studied by number of researcher and the factors which effect it has also been studied quite comprehensively both in Asian and western context but this issue has not be well studied in North African countries like Libya. In this study the variable job training and alternative job opportunities are studied less as compared to job satisfaction. The conceptual framework used for this research is that job 
training, job satisfaction and alternative job opportunities is taken as independent variable whereas turnover intention as dependent variable. The tool for data collection is questionnaire. The questionnaire is taken from the researches in past. All questions are in the form of 5 point likert-scale. The sample size is of 430 respondents which were from the Libyan oil companies. The data was analyzed and tested using Pearson's correlation. This research adds the literature in the context of HRM. Practically "the satisfaction with job is negatively connected with turnover intention" but here data trend says is vice versa. The intention to quit and job opportunities has a positive relation in between them that proved with many researches.

The previous research adds the work in the HRM background. The paper of (O'Halloran, 2012) discovers how various performances related pay (PRP) schemes manipulate employee turnover. The research also experiment the profit sharing effect on turnover. Like job training the performance related pay effect on turnover does not studies comprehensively in the researches. Two models of PRP are used namely the classic agency and probit model. Satisfaction and turnover are effected by different PRP schemes. A previous researches fact shows that PRP that is based on profitability which is negatively related to turnover. National Longitudinal Survey of Youth1979 of US contains the information about workers' job experiences. The sample size is of 6111 men and women taken who were national representative of US and between the ages of 14-22. The empirical result shows that there is unhelpful relationship between PRP and employee turnover. Even though is sufficient literature on the relationship among profit sharing and turnover, there is lesser research on the collision of PRP on turnover. This paper showed how different PRP schemes collision turnover of employee.

This is another HRM context research paper in which "perceived organizational support (POS), perceived supervisory support (PSS) and intention to leave" is studied (Tuzun \& Kalemci, 2012). The objective of current study is to identify the relation among "perceived organizational support (POS), perceived supervisory support (PSS) and intention to leave". Further this study researched whether or not "employee's individual cultural values that embrace individualism and collectivism moderate the link among perceived structure support and turnover intention." "Association of the Insurance and Reinsurance Companies of Turkey" helped in data collection procedure for this study. The tool for the collection of data is questionnaire. Out of 59 companies, 23 Turkish companies participated in the study. The questionnaire was given to the employees via their immediate supervisor. In this regard the complete anonymity of the respondents was guaranteed. The employees are given a period of three weeks to complete the questionnaire and returned to their immediate supervisor. The outcome of the study explains that PSS balance the negative relation between POS and intention to leave. It is also find that high supervisory support will lessen the ability of POS as an interpreter of intention to leave.

(Long, Ajagbeb, \& Kowang, 2014) We see how the HRM practice can help organization in reducing turnover in previous researches. This paper includes all the HRM practices which we discuss in the previous researches separately. The intention of study is to conclude the impact of HRM practices on intention to leave of employees in small and medium enterprise 
(SME) for which "HR practices" like "compensation and benefit, performance management, training and employee relations" is considered. After evaluation, "it is certain that the correlation between HRM practices and the impact on intention to leave by workers is significant. The importance of HRM practices in SMEs is critical in achieving competitive advantage." Therefore, SME should implement effective strategies and HRM practices to retain employees particularly the high performers. A proper supervision of HRM practices is vital to retain workers of SME especially. "HR professionals and line managers should work closely to make sure that performance management, administration of compensation policy, training, and relations with employees, satisfaction with pay, supervisory support, and job satisfaction" are performed in an effective manner.

Now we can see the factor customer relationship management (CRM) which effects turnover intention (Abdullateef, Yusoff,, Muktar, \& Ahmad, 2014). The present study draws "a theoretical framework" that clearly describes effects of implementation of CRM on the employee job satisfaction, qualitative overstretches and intention to quit in call centers in Malaysia. Facts from the literature exposed that, for the problem of employee turnover to be resolute and for effectiveness to be attained in the call centers, there need to be a proper incorporation of CRM dimensions. This paper has established a conceptual framework that would confirm that the dimensions of CRM are properly operated thereby bringing about preferred result in the industry. The conceptual framework model used in this paper linkage the CRM Dimensions (Customer Orientation, CRM Organization, Knowledge Management, and Technological Based CRM), Employee Job Satisfaction, Qualitative Overstretch and Intention to Quit within call center industry. In the light of the empirical arguments that justified the importance of CRM as an enterprise business concept and a vital aspect of marketing theories that can increase customer value at the same time decrease the costs thereby resulting to competitive fit. This study observed that the employment of CRM faces various problems from different firms, due to the deficiency of understanding of what it involves.

This research paper is in the context of Islamic point of view. (Hayati \& Caniago, 2012) This study examines the impact on intrinsic motivation, satisfaction with job, commitment with organization and performance of job of Islamic work moral. The respondents of this study include the population of workers who work in "Islamic banks of Bandar Lampung" inclusive of, "the Bank Muamlat, Bank Syariah Mandiri, BNI Syariah, BRI Syariah and Bank Syariah Bandar Lampung."For the data collection the questionnaire was distributed to 172 employees of the bank, but only 149 questionnaires were returned. For measuring work ethics respondent filled a Likert-scale of seven points. The result shows that the relation among "Islamic work ethic on intrinsic motivation, satisfaction with job, commitment with organization and performance of job are significant and positive." This study achieved to the conclusion, "Islamic Work Ethic (IWE) affects intrinsic motivation, satisfaction with job, commitment with organization and performance of job." Also this was discovered that intrinsic motivation and satisfaction with job behave as a moderating variable among IWE and commitment with organization and performance of job.

(Ertosun \& Erdilb, 2012) Previously we saw the impact of CRM on turnover intention now 
we will see the effect of loneliness on commitment of employees and intention to leave. Fewer studies are found on the topic of loneliness concept. The conceptual framework model used for this study is that loneliness is independent variable, turnover intention is dependent variable and affective commitment is taken as mediating variable. Data were collected through questionnaires from various sectors and different sized companies in Istanbul. The questionnaire was divided into four parts the first part include demographic belongings of employees prepared by the researchers. The five-point Likert-scale is use for the measurement of variables as in the prior studies. The second part of the questionnaire is about the loneliness of employee which is divided in two parts emotional deprivation and social companionship. The third part measures affective commitment of employees. For analyzing the data factor analyses, correlation and regression analyses is used. The research findings indicate that emotional deprivation is not effective on commitment. But emotional deprivation effect the employees decision whether to stay or leave the organization. In the conclusion loneliness is a negative factor in the end very few researches has been made on this issue.

As a conclusion of this chapter, job satisfaction which is considered to be the important factor because of its association with turnover, absenteeism and organizational commitment have significant negative relationship with turnover intentions. This chapter of literature review draws the attention on the researches which are conducted in retail sector, health sector, IT sector, telecom sector etc. but most of the researches in this literature review are related to health sector. The purpose of this chapter is to create insights for the research in Pakistan's health sector although many of the researches is conducted in health sector including in this literature review but very few researches are conducted in lower income countries.

\section{Research Methodology}

\subsection{Theoretical Framework}

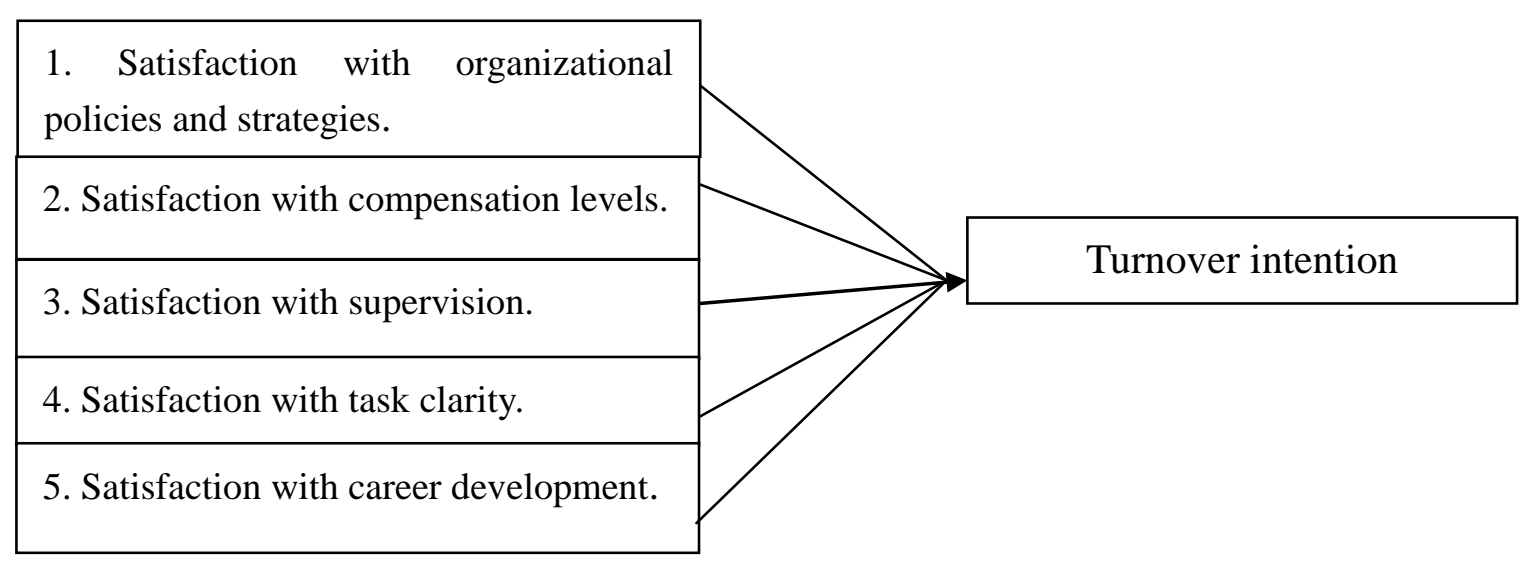

Figure 3.1. Theoretical Framework

\subsection{Hypothesis}

$\mathrm{H}_{\mathrm{a} 1}$ : There is a significant relationship between satisfaction with organizational policies and 
strategies and turnover intention.

$\mathrm{H}_{\mathrm{a} 2}$ : There is a significant relationship between satisfaction with supervision and turnover intention.

$\mathrm{H}_{\mathrm{a} 3}$ : There is a significant relationship between satisfaction with compensation levels and turnover intention.

$\mathrm{H}_{\mathrm{a} 4}$ : There is a significant relationship between satisfaction with task clarity and turnover intention.

$\mathrm{H}_{\mathrm{a} 5}$ : There is a significant relationship between satisfaction with the career development and turnover intention.

$\mathrm{H}_{\mathrm{a}}$ : There is a significant impact of satisfaction with organizational policies and strategies, satisfaction with supervision, satisfaction with compensation levels, satisfaction with task clarity, and satisfaction with the career development on turnover intention.

\subsection{Type and Nature of Study}

Our type of study is quantitative as it deals with numeric data and the nature of our study is correlation study because we will determine the relationship and association between two main variables of our study that is job satisfaction and turnover intention.

\subsection{Sampling Design}

Our industry which we have selected is hospitals of Pakistan while the sector of our study is service sector. Both private and public sector hospitals of Karachi, Pakistan are taken as the population for this study. The total number of health facilities in district Karachi is 3,550 (Rehman, Mulk, Ahmed, Ahmad, \& Kazmi, 2013) therefore this is the population size of our study. Following table shows the details of these health facilities:

Table 3.1. Number of health facilities by type

\begin{tabular}{lc}
\hline Type & Number \\
\hline Govt. Hospitals & 33 \\
Govt. Health Care Centre's & 271 \\
Govt. Dispensaries & 152 \\
Private Hospitals & 356 \\
Maternity Homes & 391 \\
Civil Dispensaries & 2,347 \\
Total & 3550 \\
\hline
\end{tabular}

Source. Master Plan Group offices, City District Government Karachi, Dec 2007.

Karachi is taken as the research site of this study. According to the table of population size and sample size by (Sekaran, 2003) our sample size is composed of 396 respondents (95\% confidence level and $5 \%$ margin of error) which is recommended by (Roger, 1995). The respondents of our study consist of registered nurses having a valid Pakistani Nursing Board License to practice nursing in hospitals of city Karachi that are situated in area North 


\section{Macrothink}

International Journal of Human Resource Studies

ISSN 2162-3058 2019, Vol. 9, No. 2

Nazimabad and Nazimabad. A survey will be held to examine the driving factors of job satisfaction and turnover intention of nurses of these hospitals. The survey method is going to be a self-administered questionnaire given out to the nurses of the hospitals of North Nazimabad and Nazimabad.

\subsection{Sampling Technique}

We will be conducting simple random sampling because in this sampling method every element in the population has a known and equal chance of being selected as a subject and it is the least bias and provides researcher with the most generalizable results (Sekaran, 2003)

\subsection{Instrumentation}

In order to gather the primary data we will use the self-administered structured survey questionnaire. Further, this questionnaire is divided into two different parts. The first part of the questionnaire consists of the questions through which the variables are measured, whereas the other part is designed to obtain the general information of our respondents that are nurses. We will visit the selected hospitals for the collection of the data whereas we may send the questionnaires via email, post and online interviews too. The following Table 3.3.3 further defines the variables of this study and their nature with each question allotted variable wise.

Table 3.2. Instrumentation development

\begin{tabular}{llll}
\hline Variables & Item allotment & Source & \\
\hline $\begin{array}{l}\text { Turnover Intention } \\
\text { (Dependent Variable) }\end{array}$ & 3 items & (Alam \& Muhammad, 2010) \\
$\begin{array}{l}\text { Satisfaction with } \\
\text { organizational policies } \\
\text { and strategies } \\
\text { (Independent Variable) }\end{array}$ & 4 items & (Alam \& $\quad$ Muhammad, & \\
$\begin{array}{l}\text { Satisfaction with } \\
\text { career development } \\
\text { (Independent Variable) }\end{array}$ & 4 items & & \\
$\begin{array}{l}\text { Satisfaction } \\
\text { supervisor } \\
\text { (Independent Variable) }\end{array}$ & 3 items & (Karavardar, 2014) & \\
$\begin{array}{l}\text { Satisfaction with } \\
\text { compensation levels } \\
\text { (Independent Variable) }\end{array}$ & 4 items & (Alam $\quad \& \quad$ Muhammad, \\
$\begin{array}{l}\text { Satisfaction with } \\
\text { task clarity } \\
\text { (Independent Variable) }\end{array}$ & 4 items & 2010) & \\
\hline
\end{tabular}




\section{Macrothink}

International Journal of Human Resource Studies

ISSN 2162-3058

2019, Vol. 9, No. 2

With reference to (Mohammad \& Alam, 2010) the Cronbach's alpha value for our variables "turnover intention, satisfaction with organizational policies, satisfaction with supervisor, and satisfaction with compensation levels" are all above 0.7. The Cronbach's alpha value for our one of the independent variable "Task Clarity" is 0.73 (Nandal \& Krishnan, 2000). Whereas the value of Cronbach's alpha for the items under "satisfaction with career development" taken from (Karavardar, 2014) are 0.78, 0.85, 0.80 and 0.86.

\section{Data Analysis}

This area of the research revolves around the data collection followed by the interpretation of the information gathered. (Mosby, 2008)

\subsection{Reliability of Instrumentation}

It tells whether a questionnaire creates the identical or alike responses with several administrations of the instrument used. (Bordens \& Abbott, 2006)

\subsection{Descriptive Analysis}

Refers to the research conducted to describe the characteristics of the collected data that includes Mean, mode, median, standard deviation and variance. (Srivastava \& Rego, 2010).

\subsection{Correlation Analysis}

It is a measurement that is quantitative in nature and is carried to see the relationship amongst two or more than two variables (Singh \& Wang, 2011). We will use Pearson Correlation method for correlation analysis that is as follows:

Table 3.3. Pearson's $r$ indices of correlation

\begin{tabular}{ll}
\hline Pearson's $r$ & Indication \\
\hline Between \pm 0.80 to \pm 1.00 & High correlation \\
Between \pm 0.60 to \pm 0.79 & Moderately high correlation \\
Between \pm 0.40 to \pm 0.59 & Moderate correlation \\
Between \pm 0.20 to \pm 0.39 & Low correlation \\
Between \pm 0.01 to \pm 0.19 & Negligible correlation \\
\hline
\end{tabular}

(Black, Babin, Anderson, \& Hair, 2010)

\subsection{Multiple Regression Analysis}

It basically deals up with the relationship that is found amongst a Dependent Variable with two or more than two variables that are independent in nature. (Srivastava \& Rego, 2010)

It is the extension of the simple regression technique that is the use of two or more independent variables. Through it a variable can be predicted on the basis of more than one predictive factor. (Kothari, 2010).

\section{Discussion and Descriptive Analysis}

The purpose of this study is to determine the effect of dimensions of job satisfaction on 
turnover intention. In order to get useful results we performed reliability testing, correlation and multiple regression.

First we perform reliability testing and all the values of Cronbach's Alpha lies above 0.6 except 2 of the item one from the variable compensation level and one from the variable task clarity which are excluded to get the value of Cronbach's Alpha above 0.6. (Sekaran, 2005).

Secondly, the correlation analysis between the independent variables and dependent variable is performed.

The correlation between the variables satisfaction with organizational policies and strategies, and turnover intention has significant relation i.e. $\mathrm{p}<0.05$ these results also confirm to the studies of Purani \& Sahadev (2008) in which they measure the job satisfaction of salesmen in India.

The correlation between the variables of our study, satisfaction with career development and turnover intention has significant relation i.e. $\mathrm{p}<0.05$ which is supported by Purani \& Sahadev (2008); Murrar \& Hamad (2013) which is related to IT industries and Bonenberger et al, (2014) which is related to health worker in Ghana.

The correlation between the variables of present study, satisfaction with supervisor and turnover intention has significant relation i.e. $\mathrm{p}<0.05$ which is conform to the studies of Purani \& Sahadev (2008); Ali (2009) which is conducted on private sector colleges and another study which is conducted in production industry (Tnay \& Slong, 2013).

The correlation between the variables of our study, satisfaction compensation level and turnover intention has significant relation i.e. $\mathrm{p}<0.05$ and this is also in conformity with (Purani \& Sahadev, 2008).

The correlation between the variables of current study, satisfaction with task clarity and turnover intention has significant relation i.e. $\mathrm{p}<0.05$ which is in conformation with the studies of Purani \& Sahadev (2008); Nandal \& Krishnan (2000).

Next we performed the regression analysis to see the impact of job satisfaction on turnover intention. We found that adjusted $\mathrm{R}$ square is 0.101 this means that there is $10.1 \%$ variance which can be predicted with the independent variables and from ANOVA table we originate that overall relationship among the variables in the model is significant i.e. $\mathrm{p}<0.05$. The regression analysis of all the independent variables is carried out in the study (Purani \& Sahadev, 2008) but there is also a moderating variable between all the aspects of job satisfaction and turnover intention, another study conducted by Ali (2009) which consists of nine facets of job satisfaction, among lecturers of NWFP colleges' shows the significant negative association between turnover intention and job satisfaction as a whole.

The table 4.2 below shows the descriptive statistics of the main variables of our study in the form of mean and standard deviation. 
Table 4.2. Descriptive statistics of variables $(n=400)$

\begin{tabular}{|c|c|c|}
\hline Variables & Mean & $\begin{array}{l}\text { Standard } \\
(\mathrm{SD})\end{array}$ \\
\hline $\begin{array}{l}\text { Satisfaction with organizational policies and } \\
\text { strategies }\end{array}$ & 4.2644 & 0.72154 \\
\hline Satisfaction with career development & 4.2606 & 0.65469 \\
\hline Satisfaction with supervisor & 4.3642 & 0.63183 \\
\hline Satisfaction with compensation levels & 3.9169 & 1.15963 \\
\hline Satisfaction with task clarity & 4.3469 & 0.62213 \\
\hline Turnover intention & 2.4075 & 1.22369 \\
\hline
\end{tabular}

Note. $1=$ strongly disagree, $2=$ disagree, $3=$ neither agree nor disagree, $4=$ agree, $5=$ strongly agree.

The value of mean is said to be at moderate level when it lies in range 1 to 5 . The table 4.2 above shows that the nurses are satisfied with the policies and strategies as its recorded Mean=4.2644, Standard Deviation=0.721. The satisfaction with career development also indicates moderate satisfaction level (Mean=4.260, $\mathrm{SD}=0.654$,). Satisfaction with supervisor (Mean=4.3642, SD=0.63183), satisfaction with compensation (Mean=3.9169, SD=1.15963). Satisfaction with task clarity (Mean=4.3469, $\mathrm{SD}=0.62213$ ). Finally respondents related to turnover intention are (Mean=2.4075, SD=1.22369). Hence after analyzing the above table we can conclude that all variables of the present study shown above have moderate level of satisfaction.

\section{Conclusion}

For this study the model that we have used comprises upon the past conducted researches to see the effects of the determinants of job satisfaction on turnover intention in health sector. For this purpose we adapted a questionnaire consisting of 24 items on Likert-scale, which was filled out by 400 nurses working in different hospitals.

After data gathering different statistical tests were applied in order to obtain analysis of data collected. Hence, through our results we can conclude that Satisfaction with Task Clarity has significant impact on Turnover intention, whereas Satisfaction with Organizational Policies and Strategies, Satisfaction with Career Development, Satisfaction with Supervision, Satisfaction with Compensation Levels have insignificant effect on Turnover intention.

This means it is important for the managers of the hospitals to clearly explain the task to the staff and make sure that the task is understood by the staff in order to reduce turnover intention from the hospital and to retain the staff. Hence, it is concluded from the result of regression output that the other four facets of job satisfaction, Satisfaction with Organizational Policies and Strategies, Satisfaction with Career Development, Satisfaction with Supervision, Satisfaction with Compensation Levels does not affect turnover intention as they are insignificant. Moreover, by looking at the ANOVA table we can conclude that our 
overall hypotheses are accepted.

\section{Acknowledgement}

I generously appreciative to my research supervisor, Dr. Muhammad Asim, whose consolation, help and support from the initial step to the last level empowered me to build up an understanding of the methodology of conducting research and empowered me to build up a comprehension of the approach of leading exploration.

Finally, I offer my respects and endowments to all those who supported and promoted me in any regard to amid the fulfilment of the research.

\section{References}

Abdullateef, A. O., Yusoff, R. Z., Muktar, S. S., \& Ahmad, I. S. (2014, May). Effects of Customer Relationship Management Strategy on Call Centre's Employee Intention to Quit: Evidence from Malaysia Call Centers. Procedia - Social and Behavioral Sciences, 130, 305-315. https://doi.org/10.1016/j.sbspro.2014.04.036

Alam, M. M., \& Muhammad, J. F. (2010). Level of Job Satisfaction and Intent to Leave Among Malaysian Nurses. Business Intelligence Journal, 3(1), 123-137.

Ali, N. (2009). Factors Affecting Overall Job Satisfaction and Turnover Intention . Journal of Managerial Sciences, II(2), 239-252.

Ali, N., \& Baloch, Q. B. (2008). Impact of Job Satisfaction on Turnover Intention: An Empirical Evidence. Journal of Managerial Sciences, II(1), 24-41.

Alniacik, E., Alniacik, U., Erat, S., \& Akcin, K. (2012). Relationships between Career Motivation, Affective Commitment and Job Satisfaction. Procedia - Social and Behavioral Sciences, 58, 355 - 362. https://doi.org/10.1016/j.sbspro.2012.09.1011

Alniacik, E., Alniacik, U., Erat, S., \& Akcin, K. (2013). Does Person-Organization Fit Moderate the Effects of Affective Commitment and Job Satisfaction on Turnover Intentions? Procedia - Social and Behavioral Sciences, 99, 274 - 281. https://doi.org/10.1016/j.sbspro.2013.10.495

Arndt, A., Arnold, T. J., \& Landry, T. D. (2006). The Effects of Polychronic-Orientation upon Retail Employee Satisfaction and Turnover. Journal of Retailing, 82(4), 319-330. https://doi.org/10.1016/j.jretai.2006.08.005

Aydogdu, S., \& Asikgil, B. (2011). An Empirical Study of the Relationship among Job Satisfaction, Organizational Commitment and Turnover Intention. International Review of Management and Marketing, 1(3), 43-53.

Biswas, S. (2010). Relationship between Psychological Climate and Turnover Intentions and its Impact on Organisational Effectiveness: A study in Indian Organisations. IIMB Management Review, 22(3), 102-110. https://doi.org/10.1016/j.iimb.2010.04.013

Blaauw, D., Ditlopo, P., Maseko, F., Chirwa, M., Mwisongo, A., Bidwell, P., . . Normand, C. 
(2013). Comparing the Job Satisfaction and Intention to Leave of Different Categories of Health Workers in Tanzania, Malawi, and South Africa. 127-137. https://doi.org/10.3402/gha.v6i0.19287

Black, W. C., Babin, B. J., Anderson, R. E., \& Hair, J. F. (2010). Multivariate Data Analysis (7 ed.). Englewood Cliffs, NJ: Prentice Hall.

Bonenberger, M., Aikins, M., Akweongo, P., \& Wyss, K. (2014). The Effects of Health Worker Motivation and Job Satisfaction on Turnover Intention in Ghana: A Cross-sectional Study. Human Resources for Health, 12(43), 1-12. https://doi.org/10.1186/1478-4491-12-43

Bordens, K. S., \& Abbott, B. B. (2006). Research Design And Methods. Boston, MA: McGraw Hill Education Pvt. Ltd.

Carmeli, A., \& Weisberg, J. (2006). Exploring Turnover Intentions among Three Professional Group of Employees. Human Resource Development Interational, 9(2), 191-206. https://doi.org/10.1080/13678860600616305

Carraher, S. M. (2011). Turnover Prediction using Attitudes towards Benefits, Pay, and Pay Satisfaction among Employees and Entrepreneurs in Estonia, Latvia, And Lithuania. Baltic Journal of Management, 06(1), 25 - 52. https://doi.org/10.1108/17465261111100905

Chatman, J. A. (1991). Matching People and Organizations: Selection and Socialization in Public Accounting Firms. Administrative Science Quarterly, 36(3), 459-484. https://doi.org/10.2307/2393204

Chen, T. Y., Chang, P. L., \& Yeh, C. W. (2004). A Study of Career Needs, Career Development Programs, Job Satisfaction and the Turnover Intentions of R\&D Personnel. International Journal of Career Management, 09(04), $424 \quad$ - 437. https://doi.org/10.1108/13620430410544364

Chen, Y., Friedman, R., \& Simons, T. (2014, September). The Gendered Trickle-Down effect How Mid-Level Managers' Satisfaction with Senior Managers' Supervision affects Line Employee's Turnover Intentions. Career Development International, 19(7), 836 - 856. https://doi.org/10.1108/CDI-02-2014-0031

Cole, S. M., \& Bruch, H. (2006, August). Organizational Identity Strength, Identification, and Commitment and their Relationships to Turnover Intention: Does Organizational Hierarchy Matter? Journal of Organizational Behavior, 27(5), 585-605. https://doi.org/10.1002/job.378

Dardar, A. A., Jusoh, A., \& Rasli, A. (2012). The Impact of Job Training, Job Satisfaction and Alternative Job Opportunities on Job Turnover in Libyan Oil Companies. Procedia - Social and Behavioral Sciences, 40, 389 - 394. https://doi.org/10.1016/j.sbspro.2012.03.205

Ertosun, Ö. G., \& Erdilb, O. (2012). The Effects of Loneliness on Employees' Commitment and Intention to Leave. Procedia - Social and Behavioral Sciences, 41, 469 - 476. https://doi.org/10.1016/j.sbspro.2012.04.057

Galletta, M., Portoghese, I., \& Battistelli, A. (2011). Intrinsic Motivation, Job Autonomy and 
Turnover Intention in the Italian Healthcare: The Mediating Role of Affective Commitment. Journal of Management Research, 3(2), 1-19. https://doi.org/10.5296/jmr.v3i2.619

Gamage, P. N., \& Buddhika, K. (2013, September). Job Satisfaction and Intention to Leave Of IT Professionals in Sri Lanka. Asia Pacific Journal of Marketing \& Management Review, 2(9), 1-11.

Grzeda, M. M., \& Prince, J. B. (1997). Career Motivation Measures: A Test of Convergent and Discriminant Validity. The International Journal of Human Resource Management, 8(2), 172-196. https://doi.org/10.1080/09585199700000047

Halepota, J. A., \& Shah, N. (2010). An Empirical Investigation of Organizational Antecedents on Employee Job Satisfaction in a Developing Country. Transforming Government: People, Process and Policy, 5(3), 280-294. https://doi.org/10.1108/17506161111155414

Hanisch, K. A., \& Hulin, C. L. (1990). Job Attitudes and Organizational Withdrawal: An Examination of Retirement and other Voluntary Withdrawal Behaviors. Journal of Vocational Behavior, 37, 60-78. https://doi.org/10.1016/0001-8791(90)90007-O

Hayati, K., \& Caniago, I. (2012). Islamic Work Ethic: The Role of Intrinsic Motivation, Job Satisfaction, Organizational Commitment and Job Performance. Procedia - Social and Behavioral Sciences, (65), 272 - 277. https://doi.org/10.1016/j.sbspro.2012.11.122

Islam, T., Ahmed, I., \& Khan, S. U. (2013). Organizational Learning Culture and Leader-Member Exchange Quality-The Way to Enhance Organizational Commitment and Reduce Turnover Intentions. The Learning Organization, 20(4/5), 322 - 337. https://doi.org/10.1108/TLO-12-2012-0079

Issa, D. M., Ahmad, F., \& Gelaidan, H. M. (2013). Job Satisfaction and Turnover Intention Based on Sales Person Standpoint. Middle-East Journal of Scientific Research, 14(4), 525-531.

Joo, B.-K., \& Park, S. (2010). Career Satisfaction,Organizational Commitment and Turnover Intention. Leadership \& Organization Development Journal, 31(6), 482-500. https://doi.org/10.1108/01437731011069999

Karavardar, G. (2014). Organizational Career Growth and Turnover Intention: An Application in Audit Firms in Turkey. International Business Research, 7(9), 67-76. https://doi.org/10.5539/ibr.v7n9p67

Kothari, C. R. (2010). Quantative Techniques (3 ed.). New Delhi: Vikas Publishing House Pvt. Ltd.

Lance, C. E. (1988, July). Job Performance as a Moderator of the Satisfaction-Turnover Intention Relation. Journal of Organizational Behavior, 9(3), 271-280. https://doi.org/10.1002/job.4030090307

Liden, R. C., \& Maslyn, J. M. (1998). Multidimensionality of Leader-Member Exchange: An Empirical Assessment through Scale Development. Journal of Management, 24(1), 43-72. 
https://doi.org/10.1016/S0149-2063(99)80053-1

Loncar, P. S. (2010). Pay Satisfaction, Job Satisfaction and Turnover Intent. Industrial Relations, 65, 470-490. https://doi.org/10.7202/044892ar

Long, C. S., Ajagbeb, M. A., \& Kowang, T. O. (2014). Addressing the Issues on Employees' Turnover Intention in the Perspective of HRM Practices in SME. Procedia - Social and Behavioral Sciences, 129, 99-104. https://doi.org/10.1016/j.sbspro.2014.03.653

Lotfi, M. H., \& Pour, M. S. (2013, October). The Relationship between Organizational Justice and Job Satisfaction among the Employees of Tehran Payame Noor University. Procedia - Social and Behavioral Sciences, 93, 2073-2079. https://doi.org/10.1016/j.sbspro.2013.10.168

Mahdi, A. F., Zin, M. Z., Nor, M. R., Sakat, A. A., \& Naim, A. S. (2012). The Relationship Between Job Satisfaction and Turnover Intention. American Journal of Applied Sciences, 9(9), 1518-1526. https://doi.org/10.3844/ajassp.2012.1518.1526

Martin, A., \& Roodt, G. (n.d.). Perceptions of Organisational Commitment, Job Satisfaction and Turnover Intentions in a Post-Merger South African Tertiary Institution. Journal of Industrial Psychology, 34(1), 23 - 31. https://doi.org/10.4102/sajip.v34i1.415

Mbah, S. E., \& Ikemefuna, C. O. (2012, July). Job Satisfaction and Employees' Turnover Intentions in Total Nigeria plc. in Lagos State. International Journal of Humanities and Social Science, 2(14), 275-287.

McCulloch, M. C., \& Turban, D. B. (2007, March). Using Person-Organization Fit to Select Employees for High-Turnover Jobs. International Journal of Selection and Assessment, 15(1), 63-71. https://doi.org/10.1111/j.1468-2389.2007.00368.x

Meyer, J. P., \& Allen, N. J. (1991). A Three-Component Conceptualization of Organizational Commitment. Human Resource Management Review, 1(1), 61-89. https://doi.org/10.1016/1053-4822(91)90011-Z

Monis, S. H., \& Sreedhara, D. T. (2011, January). Employee Satisfaction with Career Development Practices: A Comparative Study of Indian and Foreign MNC BPO Firms. Journal of Arts Science \& Commerce, II(1), 110-122.

Mosby. (2008). Mosby's Medical Dictionary (8 ed.). Elsevier Health Sciences.

Murrar, A., \& Hamad, A. (2013). Relationship between Job Satisfaction and Turnover Intention: An Empirical Study on the IT Firms in Palestine. Interdisciplinary Journal of Research in Business, 2(8), 67-83.

Nandal, V., \& Krishnan, V. R. (2000). Charismatic Leadership and Self-Efficacy: Importance of Role Clarity. Management And Laour Studies, 25(04), 232-243. https://doi.org/10.1177/0258042X0002500401

Niehoff, B. P., \& Moorman, R. H. (1993, June). Justice as a Mediator of the Relationship between Methods of Monitoring and Organizational Citizenship Behavior. The Academy of 
Management Journal, 36(3), 527-556. https://doi.org/10.2307/256591

O'Halloran, P. L. (2012). Performance Pay and Employee Turnover. Journal of Economic Studies, 39(6), 653 - 674. https://doi.org/10.1108/01443581211274601

O'Reilly, C. A., Chatman, J. A., \& Caldwell, D. F. (1991). People and Organizational Culture: A Profile Comparison Approach to Assessing Person-Organization Fit. The Academy of Management Journal, 34, 487-516. https://doi.org/10.2307/256404

Ozbag, G. K., \& Ceyhun, G. C. (2014). Does Job Satisfaction Mediate the Relationship between Work-family Conflict and Turnover? A Study of Turkish Marine Pilots. Procedia Social and Behavioral Sciences, 140, 643-649. https://doi.org/10.1016/j.sbspro.2014.04.485

Park, J. S., \& Kim, T. H. (2009). Do Types of Organizational Culture Matter in Nurse Job Satisfaction and Turnover Intention? Leadership in Health Services, 22(1), 20 - 38. https://doi.org/10.1108/17511870910928001

Purani, K., \& Sahadev, S. (2008). The Moderating Role of Industrial Experience in the Job Satisfaction, Intention to Leave Relationship: An Empirical Study among Salesmen in India. Journal of Business \& Industrial Marketing, 23(7), 475-485. https://doi.org/10.1108/08858620810901239

Rahman, M. M., \& Iqbal, M. F. (2013, June). A Comprehensive Relationship between Job Satisfaction and Turnover Intention of Private Commercial Bank Employees' in Bangladesh. International Journal of Science and Research, 02(6), 17-23.

Rehman, M., Mulk, S., Ahmed, S., Ahmad, N., \& Kazmi, S. (2013). Pakistan Emergency Situational Analysis. Karachi: Information Management and Mine Action Program Pakistan.

Roger, B. (1995). Richard J. Daley: Politics, Race, and the Governing of Chicago. Greenville, NC, United States: Northern Illinois University Press.

Sahadev, S., \& Keyoor, P. (2008). Modelling the Consequences of E-Service Quality. Marketing Intelligence \& Planning, 26(6), 605-620. https://doi.org/10.1108/02634500810902857

Salleh, R., Nair, M. S., \& Harun, H. (2012). Job Satisfaction, Organizational Commitment,and Turnover Intention: A Case Study on Employees of a Retail Company in Malaysia. International Journal of Social, Management, Economics and Business Engineering, 6(12), 702-709.

Sekaran, U. (2003). Research Methods For Business: A Skill Building Approach (4 ed.). New York, NY: Hermitage Publishing Services.

Sekaran, U. (2005). Research Methods For Business: A Skill Building Approach (4 ed.). New York, NY: John Wiley \& Sons, Inc.

Singh, D., \& Wang, Y. (2011, December). Correlation Analysis. Retrieved December 2, 2014, from Slide Share: http://www.slideshare.net/divyanshu22/correlation-analysis-12140817 


\section{Macrothink}

International Journal of Human Resource Studies

ISSN 2162-3058 2019, Vol. 9, No. 2

Spector, P. E. (1997). Job satisfaction: Application, Assessment, Cause, and Consequences. Thousand Oaks, CA: Sage Publications, 3. https://doi.org/10.4135/9781452231549

Srivastava, T. N., \& Rego, S. (2010). Business Research Methodology. New Delhi: McGraw Hill Education Pvt. Ltd.

Tnay, E., \& Slong, H. C. (2013). The Influences of Job Satisfaction and Organizational Commitment on Turnover Intention. Procedia - Social and Behavioral Sciences, 97, 201-208. https://doi.org/10.1016/j.sbspro.2013.10.223

Tuzun, I. K., \& Kalemci, R. A. (2012). Organizational and Supervisory Support in Relation to Employee Turnover Intentions. Journal of Managerial Psychology, 27(5), 518 - 534. https://doi.org/10.1108/02683941211235418

Wang, S., \& Yi, X. (2011). It's Happiness that Counts: Full Mediating effect of Job Satisfaction on the Linkage from LMX to Turnover Intention in Chinese Companies. International Journal of Leadership Studies, 6(3), 338-356.

Yin-Fah, B. C., Foon, Y. S., Leong, L. C., \& Osman, S. (2010, August). An Exploratory Study on Turnover Intention among Private Sector Employees. International Journal of Business and Management, 5(8), 57-64. https://doi.org/10.5539/ijbm.v5n8p57

Yuan, L., Yu, Y., Li, J., \& Ning, L. (2014, October). Occupational Commitment, Industrial Relations and Turnover Intention: Empirical Evidence from China. Chinese Management Studies, 08(1), 66 - 84. https://doi.org/10.1108/CMS-08-2011-0065

Yucel, İ. (2012). Examining the Relationships among Job Satisfaction, Organizational Commitment, and Turnover Intention: An Empirical Study. International Journal of Business and Management, 7(20), 44-58. https://doi.org/10.5539/ijbm.v7n20p44

\section{Copyright Disclaimer}

Copyright for this article is retained by the author(s), with first publication rights granted to the journal.

This is an open-access article distributed under the terms and conditions of the Creative Commons Attribution license (http://creativecommons.org/licenses/by/4.0/). 